\title{
EFFECTS OF TIDE ON WAVES IN THE OUTER SEINE ESTUARY AND THE HARBOR OF LE HAVRE
}

\author{
Nicolas Guillou ${ }^{1}$ and Georges Chapalain ${ }^{1}$
}

\begin{abstract}
The present study examines the influences of time-varying tide-induced water depths and currents on waves in the outer Seine estuary (southern central English Channel) and their penetration in the harbor of Le Havre and its new infrastructures Port 2000. The investigation is based on a numerical procedure which links regional phase-averaged wave modules with a local phase-resolving wave module within Port 2000 harbor. Required spatio-temporal evolutions of tidal free-surface elevation and current are computed by circulation modules. Numerical results of wave height are compared with field data collected at three wave buoys in the access harbor channel and its inner basin. Predictions exhibit a local increase (up to $30 \%$ ) of wave height induced by current refraction at slack tide in the access harbor channel. Respective mappings of the wave height modified by the tide, the water levels alone and the currents alone confirm this finding. The effect of currents on waves are pronounced along the southern breakwater of Port 2000 harbor and in the vicinity of coastal topographic features of the outer Seine estuary. Ultimate predictions of wave propagation within Port 2000 basin exhibit, however, the negligible direct influence of local ambient currents on wave height. Observed-semidiurnal waveheight variations in the inner basin are thus mainly associated with the propagation of the outer tide-induced modulation. Mappings of maximum wave-height within harbor basin reveal an increased exposition of the northern wharves at high tide and the southern western breakwater at low tide in relation to current-induced changes in the approaching-waves direction.
\end{abstract}

Keywords: Bay of Seine, English Channel, Port 2000, Le Havre, current, refraction, ARTEMIS, TOMAWAC, SWAN, TELEMAC 2D, COHERENS.

\section{INTRODUCTION}

Prediction of near-shore wave climate is of utmost interest for coastal engineering applications like harbor/inlet maintenance or morphological changes. In the last decades numerous numerical modeling have refined our understanding and quantification of wave in coastal areas like estuaries characterized by strong interactions with tidal forcings (e.g. Milbradt and Plü $\beta$ 2003, Rusu and Guedes Soares 2007, Sørensen et al. 2006). A review of major processes of wave modifications by tide is available in Holthuijsen (2007) and Davidson et al. (2008). Waves may thus experience significant changes under the effect of the tide. The variation of water depths modulates the dissipation of wave energy by bottom friction and breaking. Opposing tidal flow induces steepening of the incident wave field thus increasing the wave height. Finally the combination of time-varying water depths and currents leads to wave refraction and a semidiurnal variability of the incident wave energy at specific coastal locations. A noticeable resulting effect of these processes is the tidal modulation of wave height in nearshore regions.

Recent measurements implemented as part as an observational system to regulate the ship routing close to the harbor of Le Havre (southern central English Channel, Figs. 1 and 2) have exhibited such semidiurnal modulations of wave height. These changes reveal strong interactions between wave and tide at the scale of the outer estuarine zone of the Bay of Seine characterized by (i) spring tidal range of $7 \mathrm{~m}$ and current amplitude of $1.5 \mathrm{~m} \mathrm{~s}^{-1}$ (SHOM, 1996) and (ii) incoming annual wave height over $5 \mathrm{~m}$ (Lesourd, 2000). The purpose of the present study is to analyze the influences of the tide-induced time-varying water depths and currents on wave height in the outer Seine estuary and their penetration in the recent extension of Le Havre harbor (Port 2000) relying on a comparison between numerical predictions and available measurements.

Modeling links phase-averaged wave modules at the scale of the English Channel and the North Sea with a phase-resolving module within the harbor basin. Required spatio-temporal evolutions of tidal free-surface elevation and current are computed with circulation modules. Numerical results are compared with field data collected with two current meters and two wave buoys located in the access channel to Port 2000 and a wave buoy in its inner basin. The local increase of wave height under the effect of the tide is quantified. Three mappings of wave height modified by (i) the tide, (ii) the water levels alone, and (iii) the currents alone are established at the scale of the outer Seine estuary. Finally, the effects of current-induced refraction on wave-height modulation in the access harbor channel and

\footnotetext{
1 Centre d'Etudes Techniques Maritimes Et Fluviales, Laboratoire de Génie Côtier et Environnement, Technopôle BrestIroise, BP 5, 29280 Plouzané, France
} 
their penetration in its inner basin are investigated further.

\section{MATERIALS AND METHODS}

\section{Experiment}

Measurements used here were provided by the "Grand Port Maritime du Havre" (G.P.M.H.). The instrumentation consists of (i) two current meters $\mathrm{C} 1\left(\lambda=0.091^{\circ} \mathrm{E}, \Phi=49.476^{\circ} \mathrm{N}\right)$ and $\mathrm{C} 2\left(\lambda=0.077^{\circ} \mathrm{E}\right.$, $\left.\Phi=49.484^{\circ} \mathrm{N}\right)$ and (ii) three wave buoys H1 $\left(\lambda=0.104^{\circ} \mathrm{E}, \quad \Phi=49.465^{\circ} \mathrm{N}\right), \mathrm{H} 2 \quad\left(\lambda=0.087^{\circ} \mathrm{E}\right.$, $\left.\Phi=49.475^{\circ} \mathrm{N}\right)$ and $\mathrm{H} 3\left(\lambda=0.144^{\circ} \mathrm{E}, \Phi=49.459^{\circ} \mathrm{N}\right)$ located in the access channel to Le Havre harbor and its inner basin (Fig. 1-b).

The current measurements were realized over the two spring tidal periods of November 15-16, 2005, at point C2 and January 2-3, 2006, at point C1. The instrumentation is an upward looking Acoustic Doppler Current Profiler (ADCP) placed on the bottom.

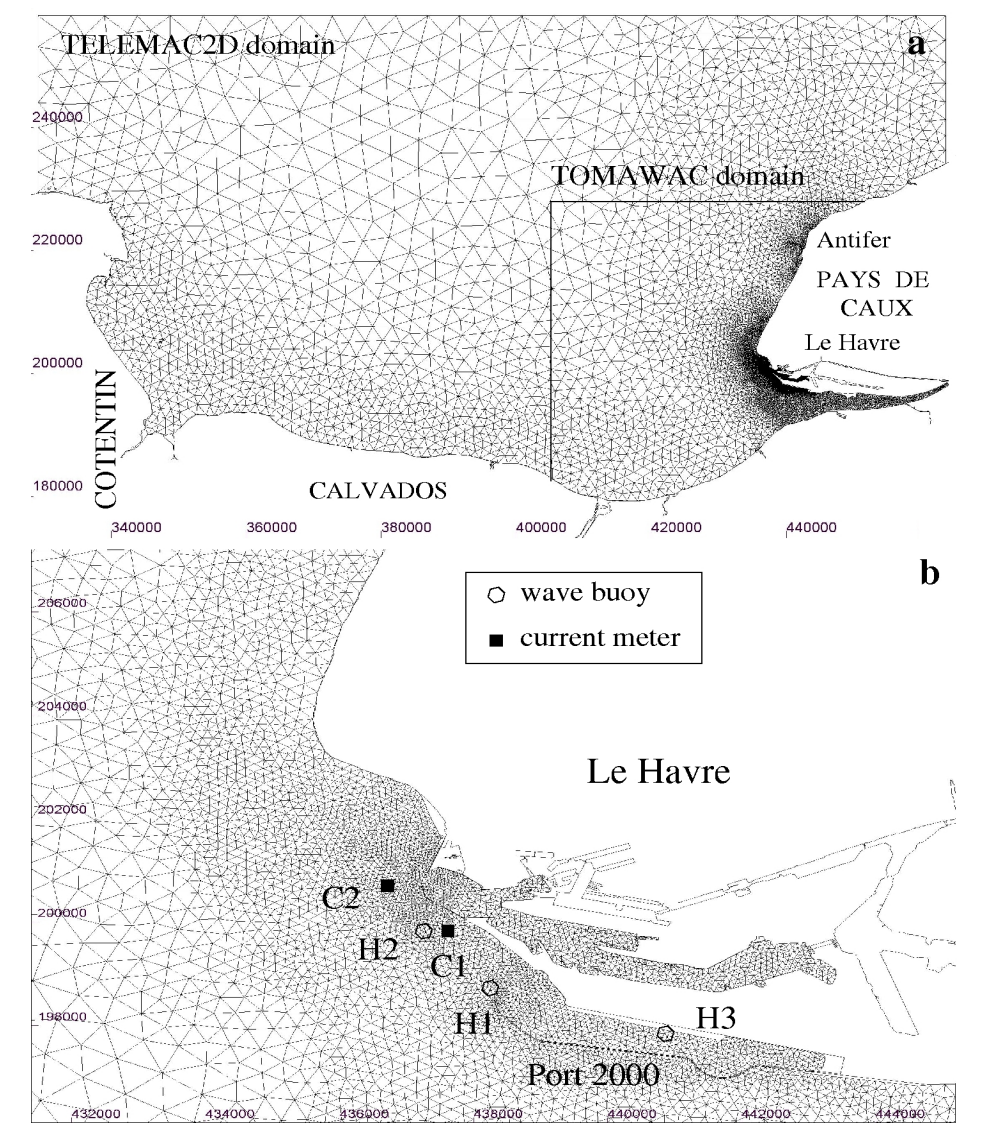

Figure 1. (a) Regional and (b) local computational domains with the locations of the measurement points.

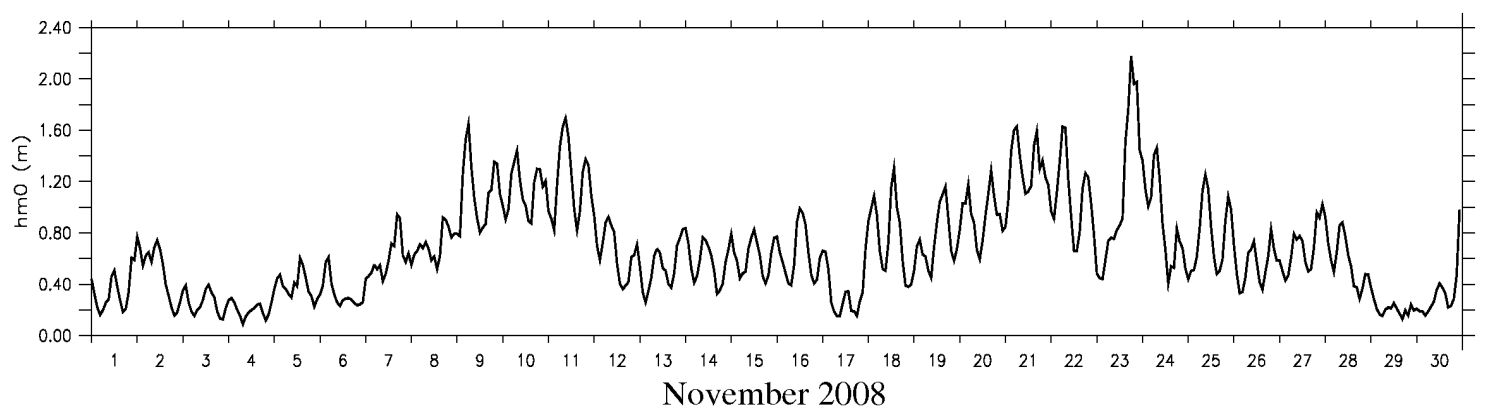

Figure 2. Measured time series of wave height at wave buoy H2 in November 2008. 
The wave buoys $\mathrm{H} 1$ and $\mathrm{H} 2$ were implemented in the access channel as part of an observational system to regulate the ship routing. The wave buoy H3 was set up to complete measurements in the inner harbor. The period analyzed here is the month of November 2008. It is characterized by a maximum significant wave height of $2.8 \mathrm{~m}$ on November 23, 2008 at point H1. The maximum tidal range reaches $7 \mathrm{~m}$ on November 14, 2008 at the tidal gauge of the harbor.

\section{Regional Modeling}

Regional simulations at the scale of the Bay of Seine and its outer estuary are performed with the modeling system TELEMAC (EDF R\&D) (Fig. 1). TELEMAC couples the phase-averaged wave module TOMAWAC (Benoit et al. 1996) with the depth-averaged circulation module TELEMAC 2D (Hervouet, 2003). This coupling considers in TELEMAC 2D the increase of the apparent bottomroughness parameter felt by the current above the wave boundary layer computed with the method of Signell et al. (1990). It integrates in TOMAWAC the effects of the time-varying water depths and ambient currents. This coupling is realized after performing computations one after another.

TOMAWAC is implemented at the scale of the outer Seine estuary from $0.245^{\circ} \mathrm{W}$ to $0.354^{\circ} \mathrm{E}$ and $49.253^{\circ} \mathrm{N}$ to $49.743^{\circ} \mathrm{N}$. The computational mesh comprises 2462 nodes and 4507 finite elements with a size of $2 \mathrm{~km}$ offshore to a few tens of meters close to the harbor of Le Havre. The module runs with 30 exponentially spaced frequencies ranging from $0.05 \mathrm{~Hz}$ to $1 \mathrm{~Hz}, 15$ evenly spaced directions ( $24^{\circ}$ resolution) and a time step of $20 \mathrm{~s}$. An uniform bottom-friction coefficient of $\mathrm{C}_{\mathrm{b}}=0.038 \mathrm{~m}^{2} \mathrm{~s}^{-3}$ is retained to parametrize the sink term of dissipation by bottom friction (Bouws and Komen 1983). TOMAWAC is driven by the wave components extracted every 90 minutes from SWAN (Simulating WAves Nearshore, Booij et al. 1999) regional simulations performed at the scale of the English Channel and the southern North Sea by Guillou and Chapalain (2012a) (Fig. 1). The time-varying water depths and currents are given every 30 minutes by TELEMAC 2D.

TELEMAC 2D is set up on a domain covering the Bay of Seine between the longitudes $1.380^{\circ} \mathrm{W}$ and $0.433^{\circ} \mathrm{E}$ and the latitudes $49.253^{\circ} \mathrm{N}$ and $50.005^{\circ} \mathrm{N}$. The computational domain comprises 8708 nodes and 16,414 finite elements with a size of $4 \mathrm{~km}$ offshore to a few tens of meters close to the harbor. The time step is set to 10 seconds. The bottom friction coefficient is computed with a Chezy's law on the basis of the heterogeneous roughness parameter derived from the observed grain-size distribution dataset in the Bay of Seine (Guillou and Chapalain 2010). The circulation module incorporates at the scale of the Bay of Seine the wind fields from the database of the National Centers for Environmental Predictions (Kanamitsu et al. 2002). TELEMAC 2D is driven by the free-surface elevations and the depth-averaged currents extracted at 1-hour intervals from regional simulations of the three-dimensional circulation module COHERENS (COupled Hydrodynamical Ecological model for RegioNal and Shelf seas, Luyten et al. 1999) at the scale of the English Channel (Fig. 1) (Guillou and Chapalain 2012a). The wave fields are provided every 90 minutes from SWAN regional simulations. Finally an averaged flow of $450 \mathrm{~m}^{3} \mathrm{~s}^{-1}$ is prescribed at the entrance of the Seine river (e.g. Waeles 2005).

Four numerical experiments are performed to investigate the effects of the tide on wave at the scale of the outer Seine estuary (Table 1). These experiments consist in integrating and/or neglecting the effects of the time-varying water depths and currents in the wave propagation module. Preliminary tests showed the moderate impact of the interactions between the wave and current bottom-boundary layers on the hydrodynamics computed by the circulation module. This makes it easier to investigate the effects of tide on waves.

\begin{tabular}{|l|l|l|l|l|}
\hline Table 1. List of numerical experiments performed. \\
\hline Experiments & NN & NS & CN & CS \\
\hline Time-Varing Water Depths & No & Yes & No & Yes \\
\hline Time-Varying Currents & No & No & Yes & Yes \\
\hline
\end{tabular}

\section{Local Modeling}

Local simulations at the scale of the inner basin of Le Havre harbor are based on the phaseresolving wave-agitation module ARTEMIS (Agitation and Refraction with Telemac on a MIldSlope) (Aelbrecht 1997, EDF R\&D 2010) of the modeling system TELEMAC. This module solves the extended mild-slope equation proposed by Booij (1981) and De Girolamo et al. (1988) on the basis of the original equation of combined refraction-diffraction (Berkhoff 1972, 1976, Smith and Sprinks 
1975) to integrate the dissipative processes associated with wave breaking and bottom friction. Wave reflection by coastal boundaries are also taken into account.

ARTEMIS is implemented on a domain covering the inner basin of Le Havre harbor and its access channel (Fig. 1). The computational domain comprises 96,415 nodes and 190,584 finite elements with a mesh size of $7 \mathrm{~m}$. Coastal boundary conditions are parameterized with the three key parameters of reflection coefficient, direction of approaching waves, and phase shift. Reflection coefficients are determined on the basis of assumed references for various types of coastal boundaries (e.g. Thompson et al. 1996). Direction of approaching waves is considered normal to the external breakwaters and tangential in the shadow zone behind. It is set to an angle of $45^{\circ}$ along the southern breakwater and the northern wharves. Normal approaching waves are, however, considered in the northwestern area and the eastern extremity of the basin. Finally, the phase shift is assumed to be zero as typically integrated (e.g. Pos 1985, Isaacson 1991).Whereas numerical developments have been achieved in incorporating the effects of ambient currents in wave-agitation computations (e.g. Cheng et al. 2005), the present modeling ignores theses effects focusing on the modulations induced by the penetration of tide-influenced waves within harbor basin. Time-varying water depths are however integrated from TELEMAC 2D numerical results. A series of stationary computation of inner-harbor agitation is performed driven by open boundaries conditions (significant wave height, period and direction) extracted from TOMAWAC predictions for case CS (Table 1) at a time interval of 1 hour and 30 minutes.

\section{RESULTS AND DISCUSSION}

\section{Comparison of Model Predictions with Point Measurements}

TELEMAC 2D numerical predictions reproduce the observed flood/ebb asymmetry of tidal currents in the access channel to Le Havre harbor (Fig. 3). The current at both measurement points predominantly flows SE and ebbs NW along the access channel to Port 2000. This current asymmetry is emblematic of the tidal hydrodynamics of the outer Seine estuary (e.g. Avoine 1981, Le Hir et al. 2001). In the present field data, it is characterized by (i) a magnitude of the flood three times greater than during ebb, and (ii) a duration of the flood limited to 4 hours whereas extended to 7 hours for ebb. The magnitude of the flood peak is approached with a difference less than $15 \%$. A slight phase lag with an averaged value less than 15 minutes is however noticed in the comparison of the measured and predicted depth-averaged current directions. This difference is less marked in the time series of the current speed. Modeling of the depth-averaged circulation constitutes, however, a satisfactory numerical approach of tidal hydrodynamic conditions for integration in the wave propagation module.

TOMAWAC predicted time series of wave height are compared with measurements at points H1 and H2 (Fig. 4). Simulations for case CS (Table 1) reproduce the semidiurnal variation of wave height for the month of November 2008. Numerical results tend to slightly overestimate the wave height at point $\mathrm{H} 2$ during the storms of November 21 and 24, 2008. This tendency is however reduced at location H1 with a difference less than $12 \%$ on November 21,2008 . Considering the difficulties to compute the tide-induced modulation of wave height (e.g. Sørensen et al. 2006), the present modeling seems acceptable to proceed further analysis.

ARTEMIS modeling is restricted to November 19-27, 2008 characterized by higher wave periods to satisfy the mesh-size constraints of the numerical resolution of a minimum mesh size compared with the wavelength (e.g. Aelbrecht 1997, EDF R\&D 2010). Numerical results reproduce the semidiurnal modulation of wave height from the entrance channel till the inner harbor (Fig. 5). Predictions approach the evolution of the significant wave height at point $\mathrm{H} 3$ while underestimating measurements at the beginning of the simulation from 19 to 20 November, 2008. Whereas predictedstorm wave-height of November 23 falls in the range of observed values, it presents a 30 min-time lag compared with measurements. Nevertheless, phase-resolving computations performed with ARTEMIS appear to be a satisfactory numerical approach of wave-height conditions at the measurement site within the harbor basin.

\section{Effects of Tide on Wave Height in the Outer Seine Estuary}

The importance of the tide in the semidiurnal wave-height modulation is exhibited by the comparison of predictions in the access channel to Le Havre harbor between cases CS and NN (Fig. 4). The wave height (i) increases up to $30 \%$ at high tide and (ii) diminishes by about $10 \%$ at low tide 

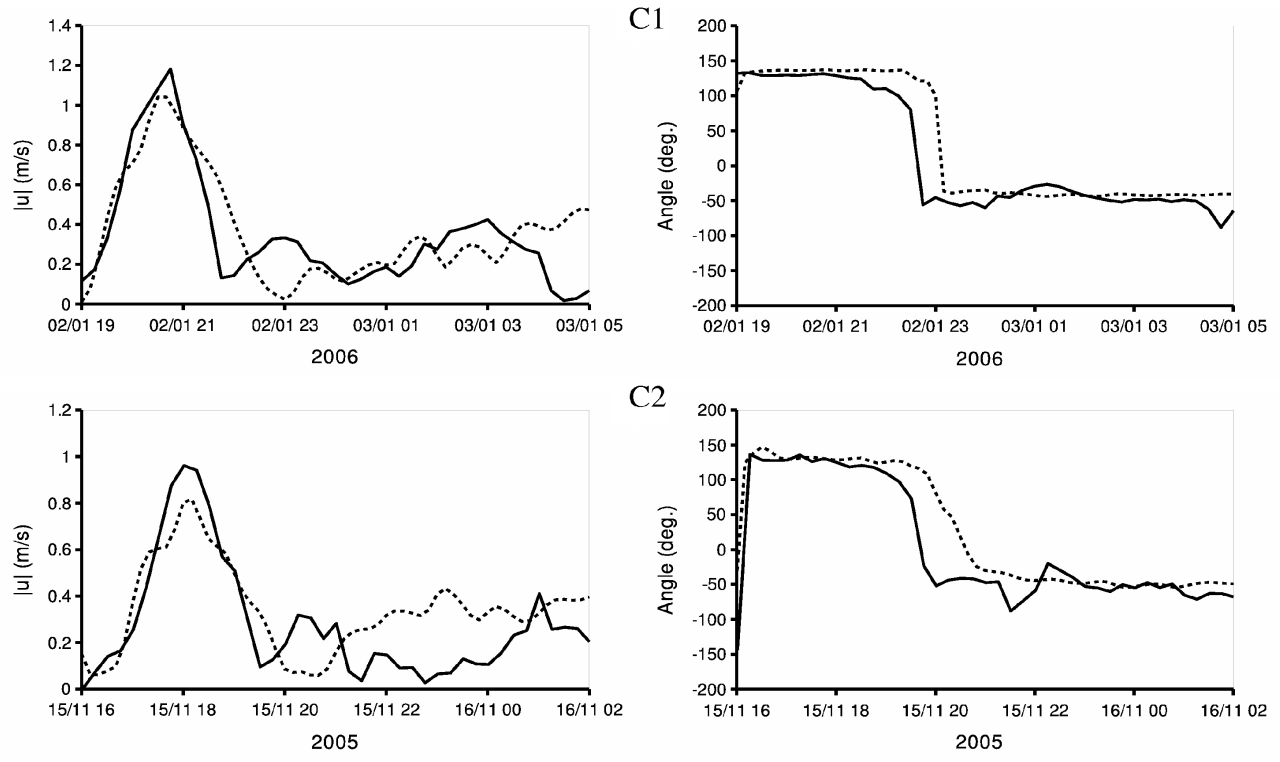

Figure 3. Measured (continuous line) and TELEMAC 2D computed (dotted line) time series of the amplitudes and directions (clockwise from the north) of the depth-averaged currents at location C1 in January 2006 and location C2 in November 2005 (from Guillou and Chapalain, 2012a).
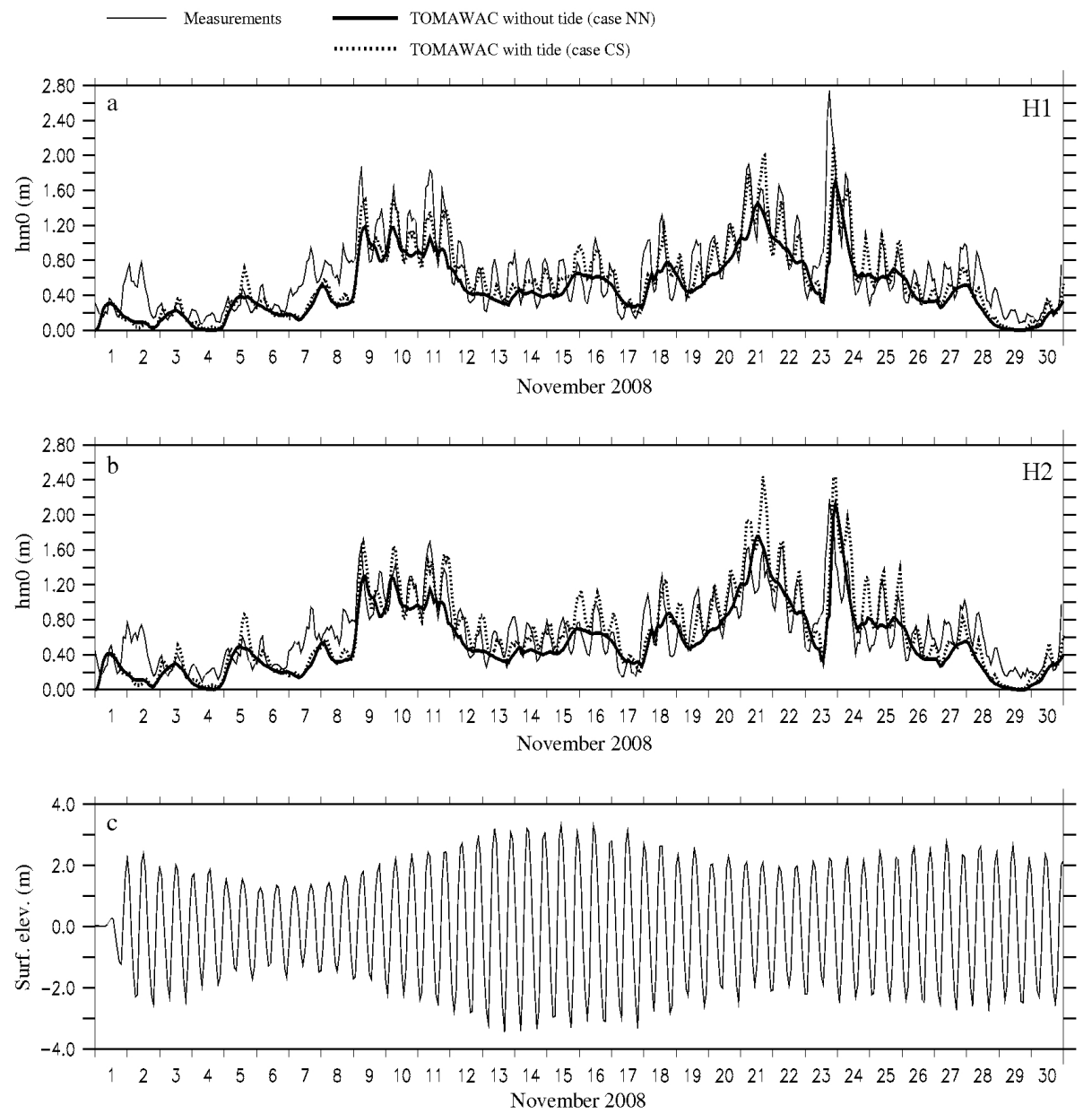

Figure 4. Measured and TOMAWAC computed for cases CS and NN time series of the significant wave height at locations (a) H1 and (b) H2 and TELEMAC 2D computed time series of (c) the free-surface elevation at location H2 in November 2008 (from Guillou and Chapalain, 2012a). 
at points $\mathrm{H} 1$ and $\mathrm{H} 2$. These variations are consistent with the numerical estimates of Wang et al. (2006) who found a tide-induced increase of wave height by 10-20\% in the Pearl River estuary (China). These modulations are particularly pronounced for significant wave height over $0.60 \mathrm{~m}$ appearing between November 9 and 25, 2008. Moderate effects of the tide are thus obtained during reduced wave conditions in the beginning (November 1-9, 2008) and the end (November 25-30, 2008) of the measurement period. Furthermore, the wave-height modulation appears to be barely sensitive to the strength of the tide during the spring-neap cycle of November 9-25, 2008.

Predictions issued from cases $\mathrm{CN}$ and CS are very similar. This comparison exhibits the negligible effect of time-varying water depths on wave-height modulations in the access channel to Le Havre harbor. The currents appear to have a major influence on these variations. The role played by tidal currents is investigated further focusing on the storm of November 9-13, 2008 at wave buoy H2 (Fig. 6). It seems difficult to assign these variations to waves steepening by the current as maximum changes appear at slack tide (T1 and T2) when the current amplitude is minimum. Furthermore, maximum wave heights are mainly obtained in following current conditions. Modulations may however be attributed to current-induced refraction. The evolutions of the wave height and the direction of the incident waves are thus closely correlated (Fig. 6). Main changes appear at slack tide (T1 and T2) characterized by maximum spatial gradients in current amplitude along the west-east wave direction. During the period of simulation, current-induced refraction changes wave direction by $10-20^{\circ}$. Incoming southeasterly waves tend to deflect to the north at high tide and the south at low tide. These variations of the wave direction modulate the exposure of the harbor entrance channel leading to semidiurnal variations of wave height at measurement sites $\mathrm{H} 1$ and $\mathrm{H} 2$.

These numerical predictions are exploited further to produce mappings of the areas where the wave heights are modified by (i) the tide, the time-varying (ii) water depths and (iii) currents (Fig. 7). Mappings are established computing the average of the absolute differences in wave heights predictions for the month of November 2008 between the different numerical experiments (Table 1). This criterion takes a mean value of $0.12 \mathrm{~m}$ under the overall effect of the tide (differences between cases CS and NN) at the scale of the outer Seine estuary. Tidal currents are found to have a major influence on wave-height modulation with an averaged criterion of $0.11 \mathrm{~m}$. Prominent effects of the time-varying water depths are, however, obtained in shallow waters (i) off the cape of La Hève, (ii) the shoals of the Seine estuary entrance, and (iii) along the southern coastline. The influence of the currents is particularly noticeable (i) at the western extremities of the access channels to the Seine River, (ii) off Villerville, (iii) close to the breakwaters of the harbor, and (iv) off the cape of La Hève.

\section{Tidal Modulation of Wave Height within the Harbor Basin}

Although effects of ambient currents are not integrated in ARTEMIS computations, numerical predictions reproduce the observed tidal modulation of wave height at point H3 (Fig. 5). The observed semidiurnal variation of wave height inside the harbor appears to be mainly associated with the propagation of the outer tide-induced modulation in the access channel. Local ambient currents are thus found to have a negligible influence on wave height within harbor basin for the period of simulation.

As mentioned before, outer modulations of wave-height are associated with changes in the approaching-wave direction through current-induced refraction. The consequences of this modulation on wave agitation within the harbor are investigated further displaying for the period of November 1927, 2008 the predicted overall maximum wave height (Fig. 8a) and the maximum wave height at high (Fig. 8b) and low (Fig. 8c) tides. Differences between Figures $8 \mathrm{~b}$ and $8 \mathrm{c}$ are found to be related to the modulation of the outer wave direction. Maximum wave heights occur at high tide, resulting in weak differences between Figures $8 \mathrm{a}$ and $8 \mathrm{~b}$. Waves of maximum heights enter the harbor along a southeastern direction, exposing the northern wharves and the southern breakwater. Maximum wave heights are naturally reduced at low tide as the outer wave height is reduced (Fig. 8c). Predictions are, however, exhibiting a slight deviation of the wave direction toward the south, increasing the agitation in the eastern part of the southern breakwater at low tide. 

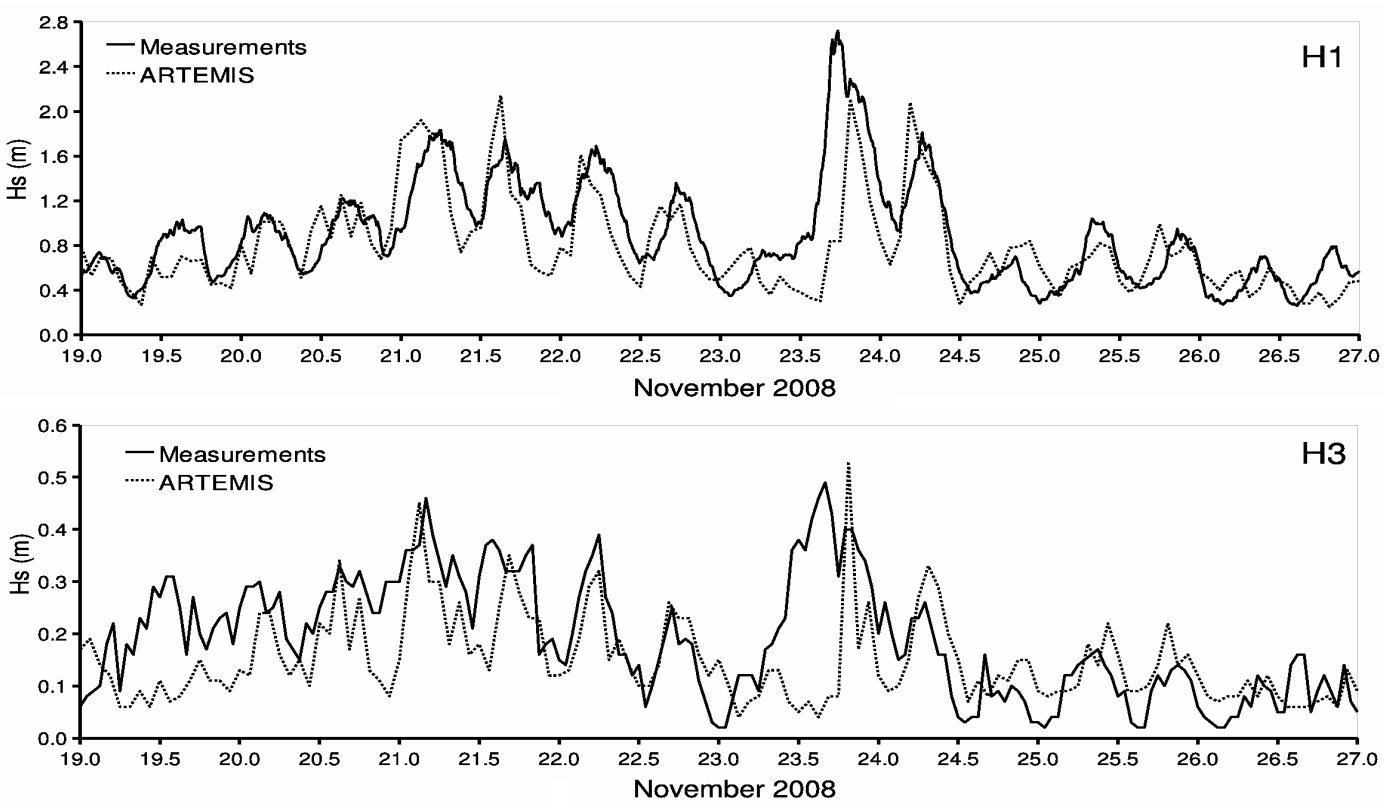

Figure 5. Measured and ARTEMIS computed time series of the significant wave height at locations $\mathrm{H} 1$ and $\mathrm{H} 3$ in November 19-27, 2008 (from Guillou and Chapalain, 2012b) .
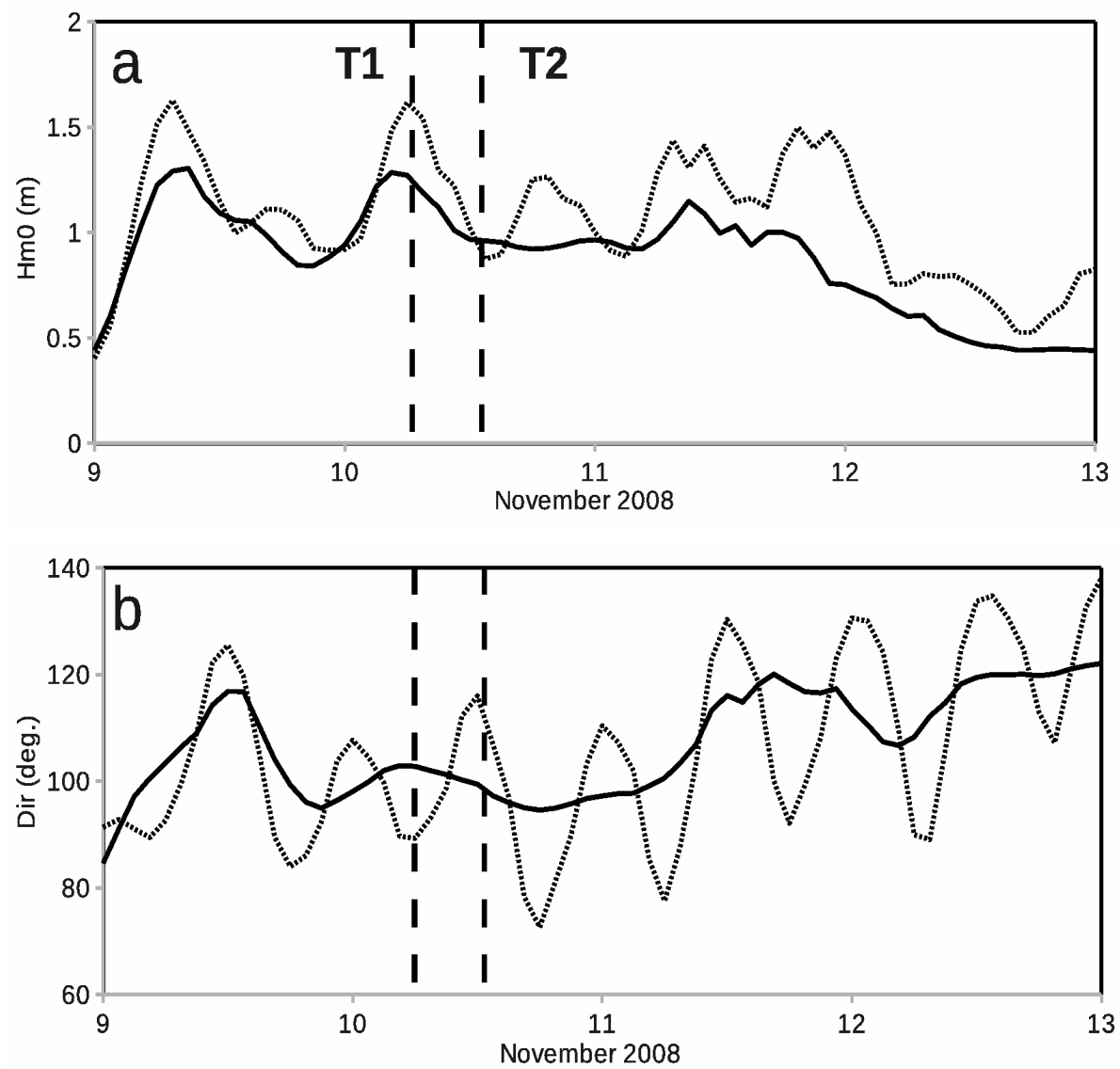

Figure 6. TOMAWAC predicted time series of (a) the significant wave height and (b) the wave direction (clockwise from the north) for cases CN (dotted line) and NN (continuous line) at location H2 in November 9-13, 2008. T1 and T2 denote times of slack tide of November 10, 2008 at high and low tides, respectively. 


\section{CONCLUSIONS}

Nested regional and local modeling systems based on the coupling of wave propagation and circulation modules have been used to investigate the effects of the tide on waves in the outer Seine estuary and the harbor of Le Havre. Numerical predictions have been compared with available waveheight measurements in the access harbor channel and its inner basin. The main outcomes of the present study are the following:

1. Computed time series of wave height reproduce the observed semidiurnal evolution at wave buoys located in the access harbor channel and its inner basin. These comparisons exhibit the importance of tide on waves in the surroundings of the harbor.

2. Current-induced refraction is found to be one the main mechanism responsible for the tidal waveheight variations in the access harbor channel. Changes in the incident wave directions modulate the exposure of the measurement points increasing by approximately $30 \%$ and decreasing by approximately $10 \%$ the wave height. Prominence of tidal currents on waves at the scale of the outer Seine estuary is confirmed with specific mappings of predicted wave-height modulations.

3. The observed semidiurnal wave-height modulations in the eastern part of the harbor basin are mainly associated with the propagation of the outer tide-induced modulation in the access channel. Local ambient currents are found to have a negligible influence for the period of simulation. Increase of the wave height within the basin is analyzed with respect to the semidiurnal tidal cycle exhibiting an increased exposition of the northern wharves at high tide and the southern western breakwater at low tide.

The integration of tide in wave simulations at the scale of the outer Seine estuary is thus fundamental for an accurate estimate of wave-height variation and its extreme values during storm events. Available observations in the access channel were performed with non-directional wave buoys. A first prospective of this research will consist in extending the comparison with observations of the approaching-wave direction in the access harbor channel. This will help to confirm and approach the variability of the wave direction associated with current-induced refraction in this area. A second prospective will consist in extending the simulation period to establish accurate climatologies of averaged and extreme wave conditions. These results will help the harbor authorities to regulate ship maneuvering and routing.

\section{ACKNOWLEDGMENTS}

We are particularly grateful to Ronan Schubel (Grand Port Maritime du Havre, France) for providing us with bathymetry and measurements of currents and waves in the access channel to Le Havre harbor and its inner basin. Simulations were performed on computer facilities CAPARMOR (Calcul PARallèle Mutualisé pour l'Océanographie et la Recherche). The present paper is a contribution to the research program of the Laboratory of Coastal Engineering and Environment (http://memphys-lgce.fr.ht). 

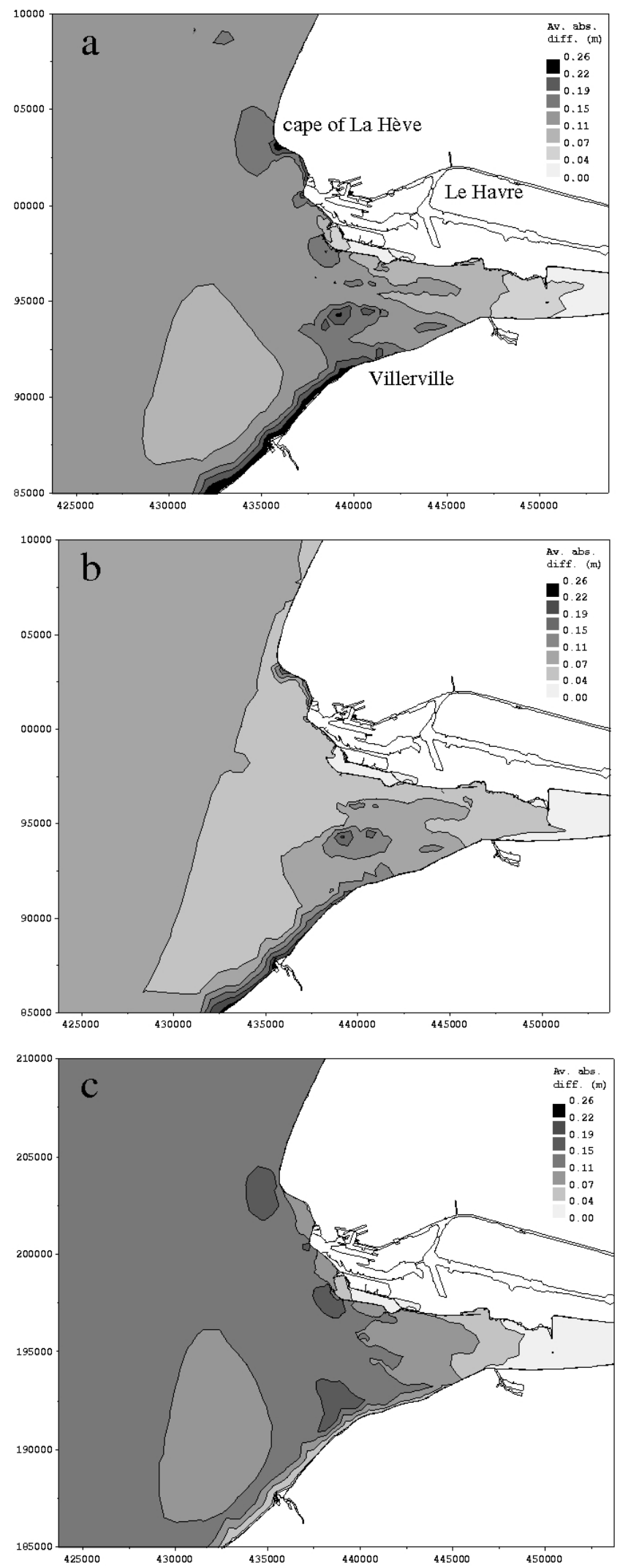

Figure 7. Average of the absolute differences between TOMAWAC-predicted significant-wave heights between cases (a) CS and NN, (b) NS and NN, and (c) CN and NN in November 2008. 

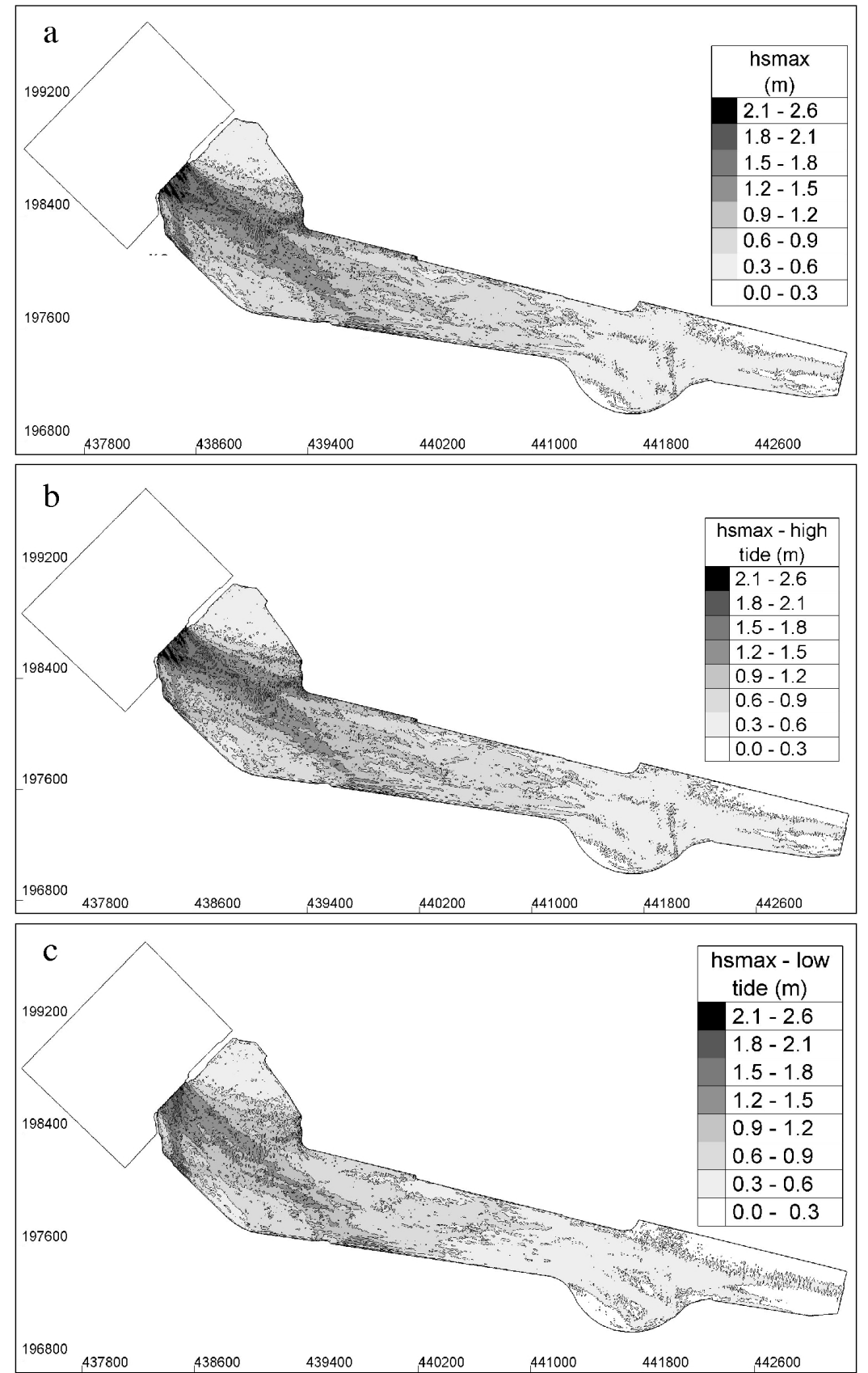

Figure 8. (a) ARTEMIS-predicted maximum wave height in November 19-27, 2008. Predicted maximum wave height at (b) high and (c) low tides in November 19-27, 2008 (from Guillou and Chapalain, 2012b). 


\section{REFERENCES}

Aelbrecht, A.M., 1997. ARTEMIS 3.0: A finite element model for predicting wave agitation in coastal areas and harbours including dissipation. In: Acinas, J.R. And Brebbia, C.A. (eds.), Computer Modelling of Seas and Coastal Regions III. International Conference. Southampton, United Kingdom: WIT Press, pp. 343-352.

Avoine, J. 1981. L'estuaire de la Seine: sédiments et dynamique sédimentaire. Thèse de doctorat de l'Université de Caen, 236 p.

Benoit, M., Marcos, F., and F., Becq. 1996. Development of a third generation shallow-water wave model with unstructured spatial meshing. In: Proceedings of the $25^{\text {th }}$ International Conference on Coastal Engineering (Orlando, USA), pp. 465-478.

Berkhoff, J.C.W. 1976. Mathematical Models for Simple Harmonic Linear Water Waves. Wave Refraction and Diffraction, Publ. ${ }^{\circ} 163$, Delft Hydraulics Laboratory, Delft, The Netherlands.

Berkhoff, J.C.W. 1972. Computation of combined refraction-diffraction. In: Proceedings of the $13^{\text {th }}$ International Conference on Coastal Engineering (Vancouver, Canada), pp. 471-490.

Booij, N.R.C., Ris, R.C., and L.H., Holthuijsen. 1999. A third generation wave model for coastal regions. 1. Model description and validation. Journal of Geophysical Research. 104, 7649-7666.

Booij, N.R.C. 1981. Gravity waves on water with nonuniform depth and current. Delft, the Netherlands: Technical University of Delft, doctoral thesis, 130 p.

Bouws, E., and G., Komen. 1983. On the balance between growth and dissipation in an extreme, depth-limited wind-sea in the southern North sea. Journal of Physical Oceanography, 13, 16531658.

Chen, W., Panchang, V., and Z., Demirbilek. 2005. On the modeling of wave-current interaction using the elliptic mild-slope, wave equation. Ocean Engineering, 32, 2135-2164.

Davidson, M.A., O'Hare, T.J., and K.J., George. 2008. Tidal modulation of incident wave heights: fact or fiction? Journal of Coastal Research, 2, 151-159, doi: 10.2112/06-0754.

De Girolamo, P., Kostense, J.K., and Dingemans, M.W. 1988. Inclusion of wave breaking in a mildslope model. In: Schrefler, B.A., Zienkiewicz, O.C. (eds.), Computer Modeling in Ocean Engineering. Rotterdam: Balkema, pp. 221-229.

EDF R\&D (Electricité De France), 2010. Agitation d'un Plan d'Eau par la Houle. Logiciel ARTEMIS. Version 6. Notice Théorique et Manuel Utilisateur. $134 \mathrm{p}$.

Guillou, N., and G. Chapalain. 2012a. Modeling the tide-induced modulation of wave height in the outer Seine estuary. Journal of Coastal Research, 28(3), 613-623.

Guillou, N. and G. Chapalain, 2012b. Modeling penetration of tide-influenced waves in Le Havre harbor. Journal of Coastal Research, 28(4), 945-955.

Guillou, N., and G. Chapalain, 2010. Numerical simulation of tide-induced transport of heterogeneous sediments in the English Channel. Continental Shelf Research, 30, 806-819.

Hervouet, J.M. 2003. Hydrodynamique des écoulements à surface libre. Modélisation numérique avec la méthode des éléments finis. Paris, France: Presses de l'Ecole Nationale des Ponts et Chaussées, $311 \mathrm{p}$.

Holthuijsen, L.H. 2007. Waves in oceanic and coastal waters. Cambridge, UK: Cambridge University Press, $387 \mathrm{p}$.

Isaacson, M. 1991.Measurement of regular wave reflection. Journal of Waterway, Port, Coastal, and Ocean Engineering, 117(6), 553-569.

Kanamitsu, M., Ebisuzaki, W., Woollen, J., Yang, S., Hnilo, J., Fiorino, M., and G.L., Potter. 2002. NCEP-DOE AMIP II reanalysis (R-2). Bulletin of the American Meteorological Society, 83, 1631-1643.

Le Hir, P., Bassoulet, P., and H., Jestin. 2001. Application of the continuous modeling concept to simulate high-concentration suspended sediment in a microtidal estuary. Coastal and Estuarine Fine Sediment Processes, 3, 229-247.

Lesourd, S. 2000. Processus d'envasement d'un estuaire macrotidal : zoom temporel du siècle à l'heure; application à l'estuaire de la Seine. Doctoral thesis of the University of Caen, $280 \mathrm{p}$.

Luyten, P.J., Jones, J.E., Proctor, R., Tabor, A., Tett, P., and K., Wild-Aden. 1999. COHERENS: A COupled Hydrodynamical-Ecological model for RegioNals and Shelf seas - Part III - Model Description (Available on CD-ROM via http://www.mumm.ca.be/coherens).Management Unit of the North Sea Mathematical Models, Report MAS3-CT97-0088, Belgique, 911 p.

Milbradt, P., and A. Plüß. 2003. Numerical modelling of wave current interaction in an estuary. 
Colombo, Sri Lanka: COPEDEC VI.

Pos, J.D. 1985. Asymmetrical breakwater gap wave diffraction using finite and infinite elements. Coastal Engineering, 9, 101-123.

Rusu, L., Bernardino, M., and C. Guedes Soares. 2011. Modelling the influence of currents on wave propagation at the entrance of the Tagus estuary. Ocean Engineering, 38, 1174-1183.

SHOM. 1996. Courants de marée en Baie de Seine de Cherbourg à Fécamp. Service Hydrographique et Océanographique de la Marine, 15 p.

Sørensen, O., Kofoed-Hansen, H., and O.P. Jones. 2006. Numerical modeling of wave-current interaction in tidal areas using an unstructured finite volume technique. Coastal Engineering, 653-665, doi: 10.1142/9789912709554 0056.

Signell, R.P., Beardsley, R.C., Graber, H.C., and A. Capotondi. 1990. Effect of wave-current interaction on wind-driven circulation in narrow, shallow embayment. Journal of Geophysical Research, 95, 9671-9678.

Smith, R. and T., Sprinks. 1975. Scattering of surface waves by a conical island. Journal of Fluid Mechanics, 72, Part 2, 373-384.

Thompson, E.F., Chen, H.S., and L.L., Hadley. 1996. Validation of numerical model for wind waves and swell in harbors. Journal of Waterway, Port, Coastal, and Ocean Engineering, 122(5), 245 257.

Waeles, B. 2005. Modélisation morphodynamique de l'embouchure de la Seine. Thèse de doctorat de l'Université de Caen - Basse-Normandie, 230 p.

Wang, C.-H., Wai, W.-H., Onyx, Li, Y.-S., and Y., Chen. 2006. Modelling of the wave-cuurent interaction in the Pearl River Estuary. Journal of Hydrodynamics, Ser. B., 18(3), Supplement 1, $159-165$. 